\title{
Retrieving Family Medicine's Lost Literature: The Journal of Family Practice 1974-1999 Archive
}

\author{
Larry A. Green, MD and James C. Puffer, MD
}

The first repository of research in family medicine in the United States was the Journal of Family Practice (JFP) (https://www.mdedge.com/familymedicine). Much of the original development, debates about family medicine and primary care, and subsequent discoveries reside in $J F P$ issues from 1974 to 1999. An archive of these issues is now available online after being somewhat lost for several years. It is a treasure-trove of information that reveals the evolution of family medicine as a discipline and remains pertinent to the current challenges and aspiration of family medicine and primary care. Investigators can benefit from checking this archive to build from prior work and avoid unnecessarily starting over. (J Am Board Fam Med 2021;34:477-480.)

Keywords: Family Medicine, Knowledge Translation, Primary Health Care, Publications, Scholarly Publishing

\section{Introduction}

After overcoming nearly insurmountable odds, including forceful opposition from multiple specialty boards and the American Academy of General Practice, the Liaison Commission for Specialty Boards approved the application of the then American Board of Family Practice (ABFP) in February 1969 and created the specialty we now know to be family medicine. ${ }^{1}$ The forces that eventually led to the establishment of the new specialty "were intimately tied to the expectations that the public had for the physicians who provided their care. To a large degree these expectations were not being met, and the answer to this dilemma was a new specialty that would train family physicians to become the personal physicians of a wanting public." ${ }^{2}$ The first 5 years of the existence of the new specialty of family medicine focused almost exclusively on the rapid expansion of training programs

This article was externally peer reviewed.

Submitted 21 October 2020; revised 3 December 2020; accepted 4 February 2021.

From the University of Colorado School of Medicine, Aurora (LAG); David Geffen School of Medicine at the University of California, Los Angeles.

Funding: None.

Conflict of interests: None.

Corresponding author: Larry A. Green, MD, University of Colorado School of Medicine, Aurora (E-mail: Larry. green@cuanschutz.edu).

See Related Article on Page 668. that would train this new brand of specialists—almost 200 new programs were created during this period of time. ${ }^{3}$ However, newly created departments of family medicine, in addition to supporting training, also focused on recruiting faculty who would conduct the research necessary to create new knowledge about the practice of family medicine and its influence on the health of the patients for whom its clinicians provided care. However, no scientific journal explicitly welcomed and focused on publishing family medicine research at that time. The fournal of Family Practice $(\mathcal{F P})$ was established in 1973 to remedy the problem. As its founding editor, John P. Geyman, MD, launched $7 F P$ from his office at the University of California Davis and continued as editor while serving as the chairman of the department of family medicine at the University of Washington. The fFP quickly became the repository for much of the early, formative work of the specialty and subsequent publications as family medicine matured.

The FFP has been, and remains, a privately owned journal that has traversed owners over the years. In 1999, Frontline Medical Communications assumed ownership of the $7 F P$ and continued the brand with a strong focus on clinical material. While subsequently published articles were freely available online, articles published during the first 25 years of existence of the FFP were not readily attainable. Concerned that much of the early literature about the specialty of family medicine would be lost, the American Board of Family Medicine (ABFM) Foundation entered into an 
agreement in 2017 with the ownership of the $\mathcal{F F P}$ to help underwrite the cost of making this archive of early family medicine literature available online as well. With the assistance and diligent efforts of Marya Ostrowski at MDedge and $7 F P$ Editor-in-Chief John Hickner, MD, this early work is now accessible online at https://www.mdedge.com/familymedicine/archivedissues/jfponline?page $=6$.

Reviewing this early work reveals that it is a treasure trove of information. In addition to accessing it directly through the URL listed above, specific articles can be located in conventional fashion using any of a number of search tools, including Google Scholar and PubMed. Direct links to the actual $7 F P$ articles may not function on various search engines requiring opening the mdedge.com URL as above to obtain the full article. We provide here a succinct summary of a variety of articles not to fully explain them or the entire archive but to illustrate the range, scope, and relevance of family medicine publications residing in the first academic family medicine journal in the United States.

\section{The First 5 Years: 1974 to 1978}

Eighteen articles composed of 7 editorials, 6 clinically oriented reviews, 2 articles focused on the education of family physicians, and 3 exploring systems under development can be found in the very first issue of $\mathcal{F F P}$. Thirty-six individuals authored these articles, only 1 being a woman. In addition to articles introducing and explaining the new journal, 2 articles ${ }^{4,5}$ initiated a multipart series defining the sort of data system all family physicians needed to have and use including morbidity indexes, family folders, geographic coding, and practice registries. That data system, with its individual, family, community, and measurement orientation, was implemented in some practices but was displaced by the arrival of the microcomputer and digitalization; its capacities remain aspirational and have yet to be duplicated in toto in 2020. This issue also included 2 other articles focused on the importance of families in family medicine, initiating what became a robust debate about the family in family medicine, an issue not yet resolved. ${ }^{6}$

The second issue in 1974 had 20 articles by 35 authors, including 3 women. One article explained a pairing system of family practice residents that partnered 2 residents with each other in both hospital and outpatient settings to sustain continuity of care in both settings and practice sharing workloads between the partners. ${ }^{7}$ Another article explained the importance of developing collaborative research models to develop the new specialty. ${ }^{8}$ The small increase in women authors signaled the subsequent, ongoing contributions and impact of women on the development of the discipline.

The third and last issue of 1974 had 18 articles, again by a spectrum of authors, and continued a strong focus on clinical care as well as a description of a "double team" approach in practice, ${ }^{9}$ a call for embedding social workers into family practices, ${ }^{10}$ and an optimistic explanation of the practical use of electronic fetal monitoring. ${ }^{11}$

Ninety-two articles were published in $7 F P$ in 1975 , many focused on practical problems faced in practice, and some of the articles in this second year changed the world. The 4-part series ${ }^{12-15}$ by Paul Frame and Stephen Carlson, 2 early champions of the application of prevention within the specialty, laid out the case for evidence-based screening and health promotion. These articles fueled the establishment of national guidelines and the eventual implementation of the United States Preventive Services Task Force chaired in 2020 by another family physician. Others explained the importance and mechanisms of auditing practice and using evidence-based, rather than expert opinion, protocols. The debate was joined about emerging "physician extenders" as welcomed colleagues or unwelcomed competition. Calls and rationales to work with internal medicine and pediatrics in residencies and to determine who is responsible for the primary care of patients appeared, not for the first time, nor the last. Defenses of hospital practice by family physicians were argued, and pleas were made to combine business and clinical data to understand practice. The central importance of establishing a research enterprise was proclaimed repeatedly, with particular attention to clarifying the nature of primary care and how to measure it, and discovering as only frontline practices could, the natural history of the problems besetting patients. Solutions to coding the content of practice were explained and tested, and the final issue of 1975, 6 years after the establishment of family practice as a specialty, contains Gayle Stephens's "Intellectual Basis of Family Practice."16 This tour de force by Dr. Stephens lays out a quartet of misunderstandings of the generalist's role and the intellectual challenges of medicine, a trio of delusions that interfere with the establishment of generalists and family physicians, 
and Adler's 5 conditions required of a branch of knowledge and an intellectual discipline. Then, this classic and seminal article espouses that patient management, not just treatment of patients, is the quintessential skill of family physicians as envisioned by the new specialty.

The next 3 years of $7 F P$ publications brought together authors from multiple sciences, disciplines, and generations. In Volumes 3 to 7 lie the birth of what was once known as RAP, the Residency Assistance Program, formalized in-training assessment of family medicine residents, and what was hailed as a quantum leap in defining family medicine, the famous "Virginia Study" 17 characterizing the content of family practice. Such things as an extensive series focused on psychiatry for family physicians, the early experience with practice-based research networks in the United States, dynamic information and debate about the plight of rural hospitals, and the use and limitation of telephones permeate issue after issue. And the voices of the founders of primary care and family medicine boom in articles such as Kerr White's "Primary Care Research and the New Epidemiology," ${ }^{18}$ Ian McWhinney's "Family Medicine as a Science,"19 and another article by Gayle Stephens, "On the Teaching and Learning of Clinical Wisdom."20

\section{Subsequent Years: 1979 to 1999}

The first issue of $7 F P$ in its sixth year of publication includes a 5 -year review of this new scientific journal in a new specialty by editor John Geyman. ${ }^{21}$ The most striking feature was steady growth in the number of submitted manuscripts from 68 in 1973 to 445 in 1978. Likewise, there was steady growth in the number of published pages from 235 in 1974 to 1465 in 1978 . $7 F P$ at that time had become the "most frequently cited journal in the world literature of the specialty (family practice)."

The subsequent years of $7 F P$ contained in the 1974 to 1999 online archive constitute a rich repository of context and content pertinent to the continuing challenges of family medicine and primary care. What is apparent in reviewing this content is how contemporary the challenges catalogued in this early work, as well as the posited solutions to many of them, remain to this day. A worldwide pandemic and the visible inequities that it has revealed beg for solutions that can only be realized by massive structural change in our health care system. The early intellectual work in the $\mathcal{F F P}$ connects to the great pause in which we currently find ourselves as a result of the pandemic and urges us to think seriously about how the roles of family, community, and family medicine can best be organized to confront the problems of collapsing primary care, fragmentation of values and services, and health and health care disparities. Reviewing this early literature suggests that family medicine can help solve the pressing problems of today, enabled by exploiting and building further from where the discipline has already been. ${ }^{22}$

\section{Conclusion}

This archive exists because of hundreds of women and men from multiple professions, disciplines, and specialties who invented, developed, practiced, studied, and innovated primary care and family medicine into their current states. Now, as FFP continues into its 69 th volume as an important source of information for primary care clinicians, this quarter of a century of work is freely available and immediately accessible to those continuing the journey toward better health, better and affordable health care, and relief of unconscionable inequities.

To see this article online, please go to: http://jabfm.org/content/ 34/3/477.full.

\section{References}

1. Adams DP. American Board of Family Practice - A History. Lexington, KY: American Board of Family Practice; 1999.

2. Green LA, Puffer JC. Family medicine at 40 years of age: the journey to transformation continues. J Am Board Fam Med 2010;23:S1-S4.

3. Puffer JC. The American Board of Family Medicine: celebrating 50 years of continuing transformation. J Am Board Fam Med 2020;33:569-74.

4. Farley ES, Jr, Treat DF, Baker CF, Froom J, Henck $\mathrm{SH}$. An integrated system for the recording and retrieval of medical data in a primary care setting:_part 1: the age-sex registry. J Fam Pract 1974;1:44-6.

5. Froom J. An integrated system for the recording and retrieval of medical data in a primary care setting: part 2: classification of diseases. J Fam Pract 1974;1:47-8.

6. Curry HB. The family as our patient. J Fam Pract 1974;1:70-1.

7. Lincoln JA. The three-year paired residency program: a solution to a teaching dilemma. J Fam Pract 1974;1:31-3. 
8. Hesbacher P, Rickels K, Zamostien B, Perloff M, Jenkins $W$. A collaborative research model in family practice. J Fam Pract 1974;1:52-5.

9. Parkerson GR. The "double-team" approach in medical care delivery. J Fam Pract 1974;1:72-3.

10. Lincoln JA, Twersky RK, O’Neil-Sale D. Social work in the family medicine center. J Fam Pract 1974;1:34-7.

11. Nochimson DF, Cetrulo CL. Intrapartum fetal monitoring. J Fam Pract 1974;1:4-9.

12. Frame PS, Carlson SJ. A critical review of periodic health screening using specific screening criteria: part 1: selected diseases of respiratory, cardiovascular, and central nervous system. J Fam Pract 1975;2:29-36.

13. Frame PS, Carlson SJ. A critical review of periodic health screening using specific screening criteria: part 2: selected endocrine, metabolic, and gastrointestinal diseases. J Fam Pract 1975;2:123-9.

14. Frame PS, Carlson SJ. A critical review of periodic health screening using specific screening criteria: part 3: selected diseases of the genitourinary system. J Fam Pract 1975;2:189-94.
15. Frame PS, Carlson SJ. A critical review of periodic health screening using specific screening criteria: part 4: selected miscellaneous diseases. J Fam Pract 1975;2:283-9.

16. Stephens GG. The intellectual basis of family practice. J Fam Pract 1975;2:423-8.

17. Marsland DW, Wood M, Mayo F. A databank for patient care, curricula, and research in family practice: 526,196 patient problems. J Fam Pract 1976;3:25-8.

18. White KL. Primary care research and the new epidemiology. J Fam Pract 1976;3:579-80.

19. McWhinney IR. Family medicine as a science. J Fam Pract 1978;7:53-8.

20. Stephens GG. On the teaching and learning of clinical wisdom. J Fam Pract 1977;4:483-6.

21. Geyman JP. The journal of family practice 1974 1979. J Fam Pract 1979;8:19-20.

22. Lesko S, Griswold K, David SP, et al. Communities of solution: the Folsom Report revisited. Ann Fam Med 2012;10:250-60. 